\title{
The Challenge of Gig Economy to Enterprise Human Resource Management
}

\author{
Gui-dan $\mathrm{Xu}^{1, \mathrm{a}}$, Hong-zhen Lin ${ }^{1, \mathrm{~b}},{ }^{*}$,Sen Yang ${ }^{1, \mathrm{c}}$, and Ying-jue Du ${ }^{1, \mathrm{~d}}$ \\ ${ }^{1}$ School of Hengda Management, Wuhan University of Science and Technology Wuhan, China \\ ${ }^{1}$ Distinct addresses: 947 He Ping Street, Hubei Wuhan 430081, China
}

\begin{abstract}
The purpose of this paper is to study the dilemma of human resource management in enterprises under the new economic model of "Gig economy". With interview methods and studying document deeply, this paper correctly understands and analyzes the dual effects of the "Gig economy" to enterprises. On the one hand, this new economic model has created a very favorable environment for the development of enterprises, but on the other hand, it has brought unprecedented challenges to the management of human resources. This paper proposes improvement measures after analyzing the embarrassing situation of enterprises. The conclusion is that in response to the problems brought about by the "Gig economy", enterprises should give full play to their subjective initiative, grasp the favorable side, strive to avoid disadvantages, and start from a reasonable system and effective management to promote their own development. At the same time, social forces such as the government and individuals should also change their behaviors and adapt to this new economic model.
\end{abstract}

Keywords-Gig Economy; Human resources; Challenges; Management

\section{INTRODUCTION}

In the State Council executive meeting held in June 2017, Premier Li emphasized the importance of boosting the healthy development of "sharing the economy". When visiting a province in the south, Premier $\mathrm{Li}$ found that there were no formal employers in the local labor market. They can change several different jobs in a day. This is similar to the "zero industry economy" in the early days of reform and opening up. So what is the "zero industry economy"? In fact, the essence of the zero-employment economy is a short-term form of work. Each person can use his leisure time, related skills or other knowledge to help others solve problems and get paid. At the same time, the company's new labor model through odd jobs is flexible. Flexible employment methods make your labor costs more lean [1].

However, with the advent of the Internet era, the odd jobs economy has been given a new meaning, and now specifically refers to a new type of employment relationship under the sharing economy. In this employment relationship, the worker only provides certain services to the employer for a certain period of time. Moreover, the odd jobs economy can also be understood as a skill economy, and people mainly earn income by virtue of their own skills. However, while the cost-effective economy and the use of labor are more convenient, the challenges faced by enterprises are also coming.
First, in the zero-employment economy model, the relationship between employees and enterprises is fluid and unstable. The loyalty of employees to enterprises is inferior to the loyalty in traditional employment relationships, which brings certain management activities to enterprises. trouble.

Second, the zero-work economy has added a certain degree of complexity and diversity to the management of corporate personnel.

\section{THE DEFICIENCY AND TRANSFERMATION OF EMPLOYEE LOYALTY UNDER THE SECOND "GIG ECONOMY"}

\section{A. Firstly, non-life-long employment, low loyalty}

There are many such cases in reality, because the lack of employee loyalty has caused a series of troubles for the company, such as the decline in service quality, lack of loyalty, and leakage of customer data. The zero-work economy model relaxes the constraint between the company and its employees, resulting in lower employee loyalty to the company. The relationship between the employer and the employee formed by the zero-work economy is a temporary relationship. This relationship cannot be maintained through the vision and mission of the company. More directly, both parties pursue the current interests as the core. When the mission is completed, the relationship is dissolved. If we analyze this phenomenon from a psychological point of view, if an employee is employed by a company for life, he will have a strong sense of belonging to the company, regardless of whether the behavior of the company is conducive to increasing his income, to a certain extent, He will work hard to do his own job and enhance the company's external image. The employees with weak loyalty are the initial starting point of their own interests. As long as they do not jeopardize their own interests, the employees in the zero-work economy mode are likely to ignore the interests of the employers for maximizing their own interests. Therefore, for the current managers, how to break this obstacle in the zero-work economy model with declining employee loyalty, and enjoy the flexible employment benefits brought by the zero-work economy is a huge problem. 


\section{B. Secondly, employees convert their loyalty to occupation and technology}

The zero-work economy emphasizes a new type of employment relationship. The original "enterprise-employee" employment contract system gradually shifts to the "platformindividual" trading model, emphasizing everyone's participation and full use of resources. Therefore, in this context, the loyalty of the original employees to the company is now more transferred to the attention of their own occupations and technology. For enterprises, this shift in loyalty has two effects: on the one hand, because employees are more concerned with their own professions and technologies, there are more and more quality resources available in the labor market. On the other hand, even employees with higher professional and technical levels may bring worse services to the company. Some highly skilled employees will feel a sense of burnout when they are recruited because of the short-term nature of the employment relationship and the superiority of the skills. He will not choose to use $100 \%$ of his efforts in exchange for his return. Instead, this Responsibility for nowhere to be held may result in a decline in the quality of the work of the employees. Therefore, it is extremely urgent for managers to find ways to break through this situation.

\section{THE COMPLEXITY AND DIVERSITY OF ENTERPRISE MANAGEMENT UNDER THE "GIG ECONOMY"}

There is no doubt that the birth of the Gig Economy has brought more possibilities and greater selectivity to the development of enterprises, which also reducing the cost of human resources. For workers, they can give full play to their professional expertise and enjoy the greatest degree of freedom, so that the whole society idle human resources are fully utilized. The rapid growth momentum of the Gig Economy, coupled with the strong support of the state, has brought great benefits to our society, but when we enjoy these achievements, we must also be aware of the increasing burden of the management of enterprises.

\section{A. Firstly, uneven level of staff in the Gig Economy}

By the end of 2014, "odd jobs" accounted for nearly $34 \%$ of the entire U.S. labor market, according to statistics. It is the Internet-based talent platform that promotes the growth of the Gig Economy, and the McKinsey Global Study estimates that by 2025 , talent platforms like Monster.com and Uber are expected to contribute up to $2 \%$ of global GDP, with more than 500 million people benefiting from the online talent platform [2]. In China, the development of online talent platform is also very good. Using such platform resources can bring huge benefits to enterprises on the one hand, and on the other hand, through transparent employment information, workers can be provided with corresponding guarantees and upgrades. Their work quality and quality of life. In addition to grassroots workers, some high-income white-collar workers or highly educated people may also choose to join the odd-working group. The professional level and related literacy of the workers in the zero-employment economic group are uneven. It is a saying that "there are birds in the forest.". In such a situation where the level of labor is not uniform and the difference is huge, it is a huge challenge for managers to make every group as satisfied as possible. Another aspect of the difference in employee levels that brings to the company is the constantly adjusting company management guidelines. The unstable relationship between employees and employers in the odd jobs economy makes the company constantly looking for quality labor. In order to implement effective management, the company must have a set of management rules, and this standard must be dynamically variable, according to different stages of employees at different stages. The characteristics are adjusted accordingly, so that the image of the company in front of the workers will also be improved, and some enterprises with passive status can also gain greater initiative.

\section{B. Secondly, accountability of employees and companies}

The drip driver murder incident that ignited the Internet in April left a huge problem for the participants in the retail economy. The responsibility for the incident should be attributed to the driver or the company. After the incident, Didi Company issued the reward for the first time and rectified the company's taxi business at the same time, and assumed the corresponding responsibility. But more importantly, we should see the issue of accountability in this case. If Didi is not a wellknown company, will it still bear the corresponding responsibility? The zero-work economy advocates a nonemployment model. There is no contractual constraint between the employee and the employer. There is no written right and obligation and a description of the accountability. When the employee's employed labor force has problems, the responsibility of the two parties is one. Need to be clear about the problem. In fact, under the zero-work economy model, because the boundaries between employees and employers are blurred, the responsibilities and obligations between the two are unclear, and dispute cases are widespread. There was a director of a garden design company who had a deep understanding of this. "At the time, the company took over a small project that needed to be built, that is, the workload of two people for half a day. I found several display men through the odds platform. In our company, it can be said that it is the normal state, and that accident happened. Some people were injured in the process, and then experienced a series of labor disputes. "The zero-work method reflects "self-employment", compared with the previous contract The employees, the zeroworkforce itself have the ability to take responsibility. Therefore, for the enterprise, the responsibility it needs to replace the employee is correspondingly reduced. So in this process, how to find a balance point to maintain a reasonable proportion of the burden of the two sides in front of the accident is a huge challenge for the current managers.

\section{Thirdly, low Social Security for employees}

According to the results of the China Sharing Economic Development Report 2017 released by the National Information Center, as of 2016, the number of people participating in the sharing of the economy reached more than 600 million, an increase of about 100 million people over the previous year. The number of service providers is about 60 million, an increase of about 10 million over the previous year. This figure is equivalent to $6 \%$ of the labor force [3]. It can be seen that the beneficiary groups of the zero-work economy are very large. However, in such a context that should have been 
highly praised, we have found that information about the impairment of the rights and interests of workers is overwhelming, and this conflict is ultimately due to the complexity of the legal relationship between employers and temporary workers.

On the one hand, insurance is generally linked to labor contracts. The de-organized work form of "small-work economy" breaks the traditional employment relationship between employers and laborers based on labor contracts, and objectively adds some complexity to the implementation of labor rights protection. On the other hand, another significant feature of the zero-work economy is that employees' salaries are settled according to the amount of work. There is no legal labor relationship between the employers and the employers. The labor relationship in the legal sense refers to the relationship of rights and obligations in the labor process established between the employer and the laborer according to law. The identification of labor relations is through a clear labor contract signed between the two parties. Article 16 of the Labor Law stipulates: "A labor contract is an agreement between a laborer and an employer to establish a labor relationship and clarify the rights and obligations of both parties. The establishment of a labor relationship shall conclude a labor contract [4]. There is no formal labor contract between enterprises, and naturally they cannot be recognized as labor relations according to formal laws. As Harris mentioned, under the current legal system in the United States, workers are in a certain working relationship. The identity may be "employee" or "independent contractor." Employees are entitled to statutory benefits and protection, while independent contractors are not necessarily [5]. In order to reduce the burden of employees' social security benefits, many companies classify the odd-work labor force as an independent contractor, so that they do not have to bear their unemployment insurance, work injury compensation, pensions, maternity leave and other benefits. In the event of a labor dispute, both parties are actually unable to defend their rights.

Therefore, for freelancers involved in the zero-work economy, the lack of social security has become a stumbling block for many people to falter. For tax collectors, it may also mean a reduction in taxable and traceable income. Studies show that the UK government's annual tax losses are about $£ 4$ billion because people choose to work part-time instead of fulltime. Experts say this will also bring new problems to HR managers, forcing them to consider issues such as confidentiality, competition and corporate culture [6].

\section{Fourthly, Low level of "security" for employees}

Zhou Jianjun, a part-time economic participant in takeaway services in Hunan province, once said that if someone Zhou Jianjun, a part-time economic participant in the takeaway service, once said that if someone criticizes him in a dream, he will wake up from his dreams because of fear. The platform evaluation system has been praised by many people, but it is Zhou Jianjun's nightmare. The evaluation mechanism of this platform is similar to the "living" threshold of practitioners on the platform. In this case, in addition to the corresponding rights can not be guaranteed, the drip driver is threatened by the customer, the take-away personnel are complained by the customer for no reason, and the incidents are endless, resulting in a lower sense of security for the employees. The reduction in employee safety directly contributes to the increase in staff mobility. The high mobility of personnel directly causes enterprises to need more frequent rotation of employees, and the management of the former employees has been broken, so to a certain extent, it increases the complexity of enterprise management.

\section{SUGGESTIONS ON THE DEVELOPMENT STRATEGY OF HUMAN RESOURCE MANAGEMENT}

The odd jobs economy has become the most popular trend now, and is accelerating the transformation of the existing professional labor market into a working labor market, disrupting and reconstructing our existing working methods on a large scale [7].

First, government departments, as government agencies, should play an active leading role. we must establish a zeroworker information database, actively build a standardized and orderly "zero-employment economy" human resources labor market platform, and form a relatively complete and fair selection mechanism to weaken the uneven level of labor. [8],Defects, improve the overall level of zero-workforce labor. we must innovate policies and systems, introduce social security, welfare, trade union systems, labor disputes and other corresponding labor market security systems, protect the rights and interests of workers in part-time work, and improve employees' Goodwill, promote the development of employee loyalty and a sense of belonging to the company. Flexible training and licensing mechanisms should be established to enable workers in the part-time economy to improve their skills and promote the sound development of human resources development and management while standardizing the workforce and improving the overall level of employee services. We must improve social insurance for workers with odd jobs. Through the introduction of corresponding laws and regulations, the social security benefits of employees in the zero-work economy system are included in the scope of the law, forming a clear and legally available legal support [9]. Furthermore, the definition of the relationship between employees and employers in the market for odd jobs is defined, and the two sides are prevented from falling into an embarrassing situation on the issue of rights and obligations.

Second, enterprises should combine their own characteristics to establish a hierarchical type of human resources evaluation mechanism. that is, different levels of different level of staff to a certain extent to implement differentiated management. The level of labor force in the casual economy is uneven, in view of this phenomenon, enterprises can take the initiative to establish a hierarchical evaluation mechanism in line with their own development goals and mission and combined with the characteristics of employees. On the one hand, to give employees a more fair protection, improve employee satisfaction and work enthusiasm; on the other hand, this kind of evaluation mechanism can also help the company to carry out better and more matching talent selection, to achieve the maximum benefits of the company. In addition, enterprises, as the main force in the development of Gig Economy, should actively 
study and formulate a series of supporting human resources training and development system, for the effective development and utilization of human resources to provide practical protection, so as to stabilize the enterprise human resources and the company's business activities.

Third, enterprises should strive to build a reliable atmosphere. In view of the low sense of security of employees, since there is no control over the behavior of customers, enterprises can improve the situation by transforming themselves. Parallel to the current customer complaints channels, enterprises can establish the corresponding staff feedback channels to accept some of the problems encountered by employees in the course of their work, to help employees deal with the corresponding problems, reduce their dissatisfaction.

Fourth, sign the normative accountability agreement. In the early stage of recruitment, the company reached an agreement with the employees on the issue of follow-up responsibility recovery. After all, coins have a positive and negative side, when we solve the challenges that Gig Economy brought to, we need also to make full use of the benefits it brings to help realize the leap development of enterprises. First, strive to adapt to the flexibility of the casual economy, for enterprises choosing the best quality staff, to create a high-quality workforce. Nowadays, enterprises can choose the corresponding employees according to their own needs at any time, instead of being tied to the previous labor contract stipulated in the length of service, life-long employment system and other standards, to meet the gradual development of enterprises in the process of different human resources and enterprise vitality needs. Second, seize the development wave of Gig Economy and reduce the operating cost of enterprises. Although the casual economy makes enterprises face the frequent movement of people, but this kind of temporary employment relationship also makes the enterprise's employment cost is lower, eliminating the personnel training and development and so on a series of costs. Enterprises can use these savings to other key aspects of the enterprise development process, and constantly enhance the competitiveness of enterprises.

\section{CONCLUSION}

To sum up, the Internet-based Gig Economy brought huge benefits to the enterprise and individuals and at the same time inevitably brought some management difficulties. In fact, for human resources managers, these challenges cover a number of areas: how to maintain declining employee loyalty, how to effectively manage a diverse and complex workforce, how to establish a more fair and just mechanism to protect the rights and interests of odd workers, how to develop a good organizational culture to achieve the organization's goals and mission, and so on. This requires the current managers to be more agile, to prepare for a new type of employment relationship, to seek the balance between the enterprise and multi-stakeholder, to draw on each other's strengths, to take full advantage of the benefits of the odd job economy, but also to actively correspond to its shortcomings, to achieve the cooperative development of enterprises and odd jobs market.

\section{ACKNOWLEDGEMENT}

This research was financially supported by the project of innovative and entrepreneurial training program for provincial university students in Hubei in 2017: Study on the influence on their employment and Entrepreneurship of the college students' participation in the zero work economy, NO: 201710488037.

\section{REFERENCES}

[1] Big Bull's house. "What the Prime Minister said yesterday is what the ' Gig Economy' really is." 2017.6. (In Chinese)

[2] Mantiu. New challenges in the management of odd jobs [J]. New era in China, 2017 (11). (In Chinese)

[3] Wu Hui June. "There is no burden to do this, but there is no guarantee""Gig Economy" calls for flexible social security [J]. Half Moon Talk, 2018 (3): 76-77. (In Chinese)

[4] Zhu Haiqiang. "Three standards for the identification of labor relations". 2012. (In Chinese)

[5] Seth D. Harris, Wang Yuxi. Practitioners, Security and Welfare in the "Working Economy" in the United States [J]. Global Law Review, 2018(4).

[6] Human capital Management. "The Gig Economy is here, what are we going to do? ".2017.04. (In Chinese)

[7] Zheng Yichuan. "Working Economy" Comes [J]. Modern Commercial Bank, 2018(1). (In Chinese)

[8] Liu Zhenchun, Jiang Lan. A probe into the development strategy of "casual economy" of migratory birds ' human resources under the background of "half year economy" in Hainan [J].Modern state-owned enterprise research, 2017 (4). (In Chinese)

[9] Seth D. Gangan. Harris, Wang Yuping. Practitioners, guarantees and benefits in the "Gig Economy" of the United States [J].Global Law Review, 2018 (4). (In Chinese)

[10] Shanyi, Yianhai. Let the "Gig Economy" zero without Chaos [J].Today, Zhejiang, 2015 (24): 44-44. (In Chinese) 